\title{
Time-Limited Consolidation and Task Interference: No Direct Link
}

\author{
Marin Been, ${ }^{1}$ Bert Jans, ${ }^{1}$ and Peter De Weerd ${ }^{1,2}$ \\ ${ }^{1}$ Department of Cognitive Neuroscience, Faculty of Psychology and Neuroscience, Maastricht University, 6200 MD Maastricht, the Netherlands, and \\ ${ }^{2}$ Donders Institute for Brain, Behaviour, and Cognition, Radboud University, 6500 HB Nijmegen, the Netherlands
}

Perceptual skills improve with daily practice (Fahle and Poggio, 2002; Fine and Jacobs, 2002). Practice induces plasticity in task-relevant brain regions during an "offline" consolidation period thought to last several hours, during which initially fragile memory traces become stable (Karni, 1996; Dudai, 2004). Impaired retention of a task if followed by training in another task is considered evidence for the instability of memory traces during consolidation (Dudai, 2004). However, it remains unknown when after training memory traces become stable and resistant against interference, where in the brain the neuronal mechanisms responsible for interference are localized, and how these mechanisms produce interference. Here, we show in human participants strong interference between two visual skilllearning tasks for surprisingly long time intervals between training periods (up to $24 \mathrm{~h}$ ). Interference occurred during asymptotic learning, but only when stimuli were similar between tasks. This supports a strong contribution to interference of low-level visual cortical areas (Karni and Bertini, 1997; Ahissar and Hochstein, 2004), where similar stimuli recruit overlapping neuronal populations. Our finding of stimulus-dependent and time-independent interference reveals a fundamental limit in cortical plasticity that constrains the simultaneous representation of multiple skills in a single neuronal population, rather than a time-limited consolidation process.

\section{Introduction}

Consolidation is classically defined as a several-hours-long, timelimited process of neuronal plasticity following a learning experience during which initially fragile memory traces become stabilized (Dudai, 2004). In the domain of skills, a form of long-term memory (LTM) (Kandel et al., 2000), the hypothesized fragility of implicit memories during consolidation predicts interference with traininginduced gains in behavioral expertise in a task if it is followed by training in another task within a restricted time interval (behavioral interference).

However, reports of behavioral interference have been inconsistent. It is not a universal finding (Aberg and Herzog, 2010), and in studies that did report interference, it was found for widely varying time intervals, from $0 \mathrm{~h}$ up to $4 \mathrm{~h}$ in some studies (Brashers-Krug et al., 1996; Shadmehr and Holcomb, 1997; Seitz et al., 2005), to $24 \mathrm{~h}$ up to a week in others (Goedert and Willingham, 2002; Caithness et al., 2004; Zhang et al., 2008). These findings raise fundamental questions about the notion of time-limited consolidation and its relation to behavioral interference.

Behavioral interference is frequently linked with the interruption of time-limited cellular consolidation processes (Dudai,

\footnotetext{
Received Feb. 25, 2011; revised Aug. 24, 2011; accepted Aug. 29, 2011.

Author contributions: P.D.W. designed research; M.B. and P.D.W. performed research; M.B., B.J., and P.D.W. analyzed data; M.B. and P.D.W. wrote the paper.

This work was supported by a VICl grant to P.D.W. (No. 453-04-002). We thank Eric Lowet, David Arnoldussen, Astrid Valles, and Mark Roberts for their help and/or comments, and all participants.

Correspondence should be addressed to Marin Been, Department of Cognitive Neuroscience, Faculty of Psychology and Neuroscience, Maastricht University, P.0. Box 616, 6200 MD, Maastricht, The Netherlands. E-mail: marin.been@maastrichtuniversity.nl.

DOI:10.1523/JNEUROSCI.1046-11.2011

Copyright $\odot 2011$ the authors $\quad 0270-6474 / 11 / 3114944-08 \$ 15.00 / 0$
}

2004), but may also reflect overlap between neuronal populations involved in storing memory traces for different tasks (O'Reilly and Rudy, 2001). The latter factor may contribute to the variable results in prior studies, which have limited themselves to the very first session (Brashers-Krug et al., 1996; Shadmehr and Holcomb, 1997; Goedert and Willingham, 2002; Caithness et al., 2004) or first few sessions (Seitz et al., 2005; Zhang et al., 2008) of skill learning. During early learning, networks in high-level cortical regions orchestrate strategic choices, as well as attentional and motivational allocation in response to specific task demands, instructions, and context (Willingham, 1999; Hochstein and Ahissar, 2002; Doyon et al., 2003). Therefore, high-level networks involved in memory storage in two subsequent tasks may overlap or not, based on variables that are difficult to control. Consequently, opposite conclusions in similar studies of behavioral interference are reported (Seitz et al., 2005; Aberg and Herzog, 2010), although Hung and Seitz (2011) suggest an additional explanation involving eye-movement control and procedural divergences.

If overlap between neuronal populations contributing to memory traces yields behavioral interference, the time window of behavioral interference cannot simply depend on the time course of cellular plastic processes occurring if a task had been trained in isolation. Instead, behavioral interference may depend strongly on the success of a systems-level process by which memory traces that may overlap initially become segregated. Thus, behavioral interference may depend more on an often unpredictable overlap between memory traces at a population level than on the more predictable time course of known cellular plastic processes.

Because the contribution of representational overlap of memory traces to behavioral interference cannot be easily tested dur- 
ing early learning, we tested it during asymptotic learning. Here, memory storage recruits stimulus-specific populations in lower (sensory) cortical areas (Karni and Bertini, 1997; Hochstein and Ahissar, 2002; Ahissar and Hochstein, 2004), which permits testing the overlap between populations involved in memory storage on behavioral interference by simple stimulus manipulations.

\section{Materials and Methods}

Participants. All 29 (17 female, 12 male) participants had normal or corrected-to-normal visual acuity, gave written informed consent for all parts of the experiment, and were debriefed following completion of data acquisition. Participants were financially compensated for their participation. Participants were carefully selected on their motivation to participate in a long-term learning study. After their reaction to an advertisement, participants were invited for an interview in which general information was given about the experiment, and in which the importance of physical and mental fitness and sufficient sleep was emphasized. Participants were then sent home to carefully consider their decision and to recontact us within a few days to let us know their decision.

Stimuli, apparatus, and task. Participants performed a visual orientation discrimination task (ODT) in which they indicated whether an oriented stimulus was tilted clockwise or counterclockwise with respect to a (never-shown) reference orientation of $135^{\circ}$. Stimuli consisted of Gabor patches $(0.75$ cycles/deg spatial frequency, $50 \%$ Michelson contrast $)$ presented on a PC monitor (19 inch screen size, $60 \mathrm{~Hz}$ refresh rate, $1280 \times$ 1024 pixel resolution) in one of the four quadrants of the visual field depending on condition $\left(3^{\circ}\right.$ diameter at $6^{\circ}$ eccentricity) while participants were seated in a dimly lit room. Average luminance of stimuli and of the gray background was $56 \mathrm{~cd} / \mathrm{m}^{2}$. Participants rested their head in a chin rest to stabilize head position relative to the stimulus monitor. Eye position was monitored with an infrared eye camera $(60 \mathrm{~Hz}$ sampling rate Viewpoint Eye Tracker v.2.8.3, Arrington Research). A trial started with a blank gray screen, followed by presentation of a white fixation dot at the middle of the screen. In the first $500 \mathrm{~ms}$ of presentation of the fixation dot, participants were instructed to orient their eyes toward the fixation dot. This was followed by a $750 \mathrm{~ms}$ period in which accurate fixation would initiate another $250 \mathrm{~ms}$ period in which fixation was to be maintained, followed by a $500 \mathrm{~ms}$ presentation of the Gabor stimulus. Participants responded with their right index (left arrow key on keyboard) or middle finger (right arrow key on keyboard), respectively representing a counterclockwise or clockwise deviation from the reference orientation. The response window was $1000 \mathrm{~ms}$. Participants received feedback on their response by a brief color change of the fixation dot (green for correct, red for incorrect). Stimulus presentation and response recording were performed using Cortex (v.5.9.6; NIH freeware for psychophysical and neurophysiological experimentation). Trials with eye position deviations beyond $1.5^{\circ}$ relative to the fixation dot were aborted and replaced by a new randomly generated trial. Trials in which no response was given were also randomly replaced.

Training protocol. Training was separated into two periods (Fig. $1 B$ ). During a first training period (P1), just-noticeable differences (JNDs) in orientation were determined at an oblique reference orientation $\left(135^{\circ}\right)$ in an Experimental $\left(\mathrm{E}_{135}\right)$ and a Control quadrant $\left(\mathrm{C}_{135}\right)$. After a time interval $\Delta T(0,0.5,1,3,6$, or $24 \mathrm{~h})$, additional training was given in a second training period (P2) at the same stimulus location in the experimental quadrant using reference orientations $105^{\circ}\left(\mathrm{E}_{105}\right)$ and $165^{\circ}\left(\mathrm{E}_{165}\right)$ (Fig. $1 B$ ). For each condition, learning curves were measured over 15 sessions. During each session, two blocks of four JNDs in orientation discrimination were determined. Within training periods, the quadrant order was counterbalanced across days/participants. For all but one time interval $(\Delta 24 \mathrm{~h})$ between P1 and P2, the training periods were done on the same day. Although testing schedules differed between participants, they were all tested during daytime, and within participants, testing schedules were kept constant for the duration of the experiment. In the $24 \mathrm{~h}$ interval, $\mathrm{P} 1$ and $\mathrm{P} 2$ training took place on separate consecutive days, so two complete sessions were collected in a time span of a work week. In the experiment in which interference was compared for orientation dif-

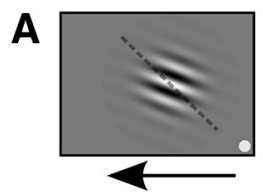

B
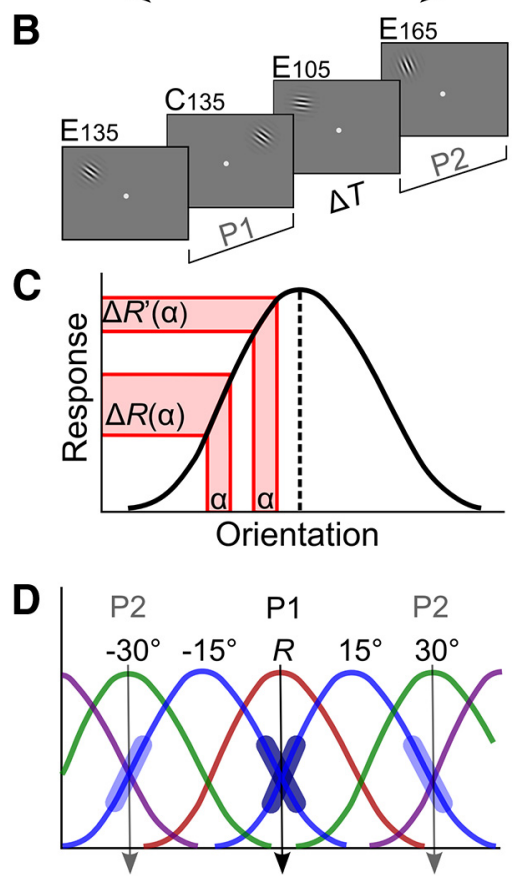

Figure 1. ODT and training-induced tuning changes in single neurons. $\boldsymbol{A}$, Gabor stimuli and task. Participants fixated in the center of the screen while covertly attending the Gabor patch in an upper (left/right) quadrant of the visual field. Participants indicated the clockwise or anticlockwise deviation of the stimulus relative to a never-presented reference (in this case $135^{\circ}$; dashed line shows reference for illustrative purposes) by pressing the right or left arrow key on a computer keyboard. Feedback was given by a change in color of the fixation dot (green, correct; red, incorrect). Trials with fixation errors $\left(>1.5^{\circ}\right.$ from fixation) were aborted (Arrington Research), and $84 \%$ correct staircase JNDs were determined (implemented in CORTEX 5.9.6, NIH freeware). B , Testing paradigm. Participants were tested in four conditions (4 JNDs of $\sim 100$ trials per condition). In training period $\mathrm{P} 1$ participants were trained at a $135^{\circ}$ reference orientation in upper left and right quadrant. One upper quadrant served as a control $\left(C_{135}\right)$. The other was the experimental quadrant $\left(\mathrm{E}_{135}\right)$, where $\mathrm{P} 1$ training after a variable time interval of rest $(\Delta T)$ was followed by training in a second period $\mathrm{P} 2$ at reference orientations $105^{\circ}\left(\mathrm{E}_{105}\right)$ and $165^{\circ}\left(\mathrm{E}_{165}\right)$. C, Tuning curve of an orientation selective cell is most discriminative at its flanks. A difference $\alpha$ between two orientations on the flanks of the tuning curve will yield a differential response $\Delta R(\alpha)$ that is larger than the differential response $\Delta R^{\prime}(\alpha)$ yielded by the same difference between two orientations closer to the neuron's preferred orientation (dashed line). D, Our experimental design is informed by prior research showing that extensive training in orientation discrimination invoking asymptotic performance (Vogels and Orban, 1985; Schoups et al., 1995) selectively modified flank slopes of tuning curves in V1 and V4 neurons (Schoups et al., 2001; Raiguel et al., 2006). As V1 neurons are more narrowly tuned to orientation (David et al., 2006), and are probably more crucial during final asymptotic performance, we used V1 tuning properties to predict conditions of behavioral interference. In a V1 population neurons with tuning curve peaks about $15^{\circ}$ away (blue curves) from a trained reference orientation $R\left(135^{\circ}\right)$ (red curve) sharpen their tuning curve flanks (fat dark blue line segments) overlapping with the reference orientation. Extrapolating this idea, we predicted that following up P1 training at the reference orientation $R$ with subsequent, $\mathrm{P} 2$ training at $R \pm 30^{\circ}$ (green curves) would cause interference with training at $R$. P1 training at $R$ and subsequent $\mathrm{P} 2$ training at $R \pm 30^{\circ}$ both require plasticity in neurons with preferred orientations at $R \pm 15^{\circ}, \mathrm{P} 1$ training should increase the slope of flanks in tuning curves overlapping with $R$, and $P 2$ training the slope of flanks overlapping with the $+30^{\circ}$ and $-30^{\circ}$ orientations (fat light blue line segments). We hypothesized that one requirement would counteract the other, leading to behavioral interference at $R$ [P2 training is also expected to lead to steepening of flanks of $\pm 45^{\circ}$ neurons' tuning curves (in purple)]. 
ferences of $90^{\circ}$ and $30^{\circ}$ between $\mathrm{P} 1$ and $\mathrm{P} 2$ reference orientations, the upper quadrants were the experimental quadrants in which interference was tested, and the control quadrant was in one of the lower quadrants. Within upper quadrants, the assignment of conditions was counterbalanced over participants, and the same held for the assignment of the control quadrant to the lower quadrants.

Data and analyses. JNDs were determined using a Wetherill and Levitt staircase that tracked an $84 \%$ correct performance. Measurements were terminated after 14 reversal points or when a total of 120 trials was reached (on average, $\sim 100$ trials were performed per staircase), and computed as the geometric mean of the last 10 reversal points. During the initial session, the starting orientation difference was set at a large value. In later sessions, measurements started at the threshold level of the previous day. In total, one block of four staircases was performed in 20-30 min for each condition. All experiments consisted of four blocks, except for the experiment that included a quadrant in which P2 training was performed at a reference orientation orthogonal to the reference used for P1 training. In that experiment, daily sessions consisted of six or seven blocks, the latter case corresponding to "double" training (see Fig. 6A). All analyses in the current paper were performed on JNDs resulting from averaging per block of four staircases.

To quantify specific aspects of the learning curves, we used a piecewise nonlinear regression fitting procedure. The piecewise fit consisted of two parts: a nonlinear (exponential) decreasing function, and a monotonically decreasing linear function. The nonlinear part of the piecewise fit was constrained by taking the mean of the first eight staircases (two sessions) as its starting point. A constraint on the linear part of the piecewise fit was imposed by fixing the end point to the average of the last three sessions. Given these constraints, the shape parameters of the nonlinear and linear part and the positioning of the transition between the nonlinear and linear part along the learning curve were algorithmically optimized to best fit the data. The position along the learning curve of the transition point from exponentially to linearly decreasing function after optimization is defined as the inflection point (IP), and estimates the beginning of asymptotic learning.

\section{Results}

This study was designed to investigate the effect of overlap between the neuronal populations that are likely to be involved in memory formation for two tasks upon behavioral interference between the tasks. In both tasks, we tested perceptual skill learning in an orientation discrimination paradigm (see Materials and Methods), in which participants judged the clockwise or anticlockwise deviation of a Gabor stimulus from a reference orientation (Fig. 1 $A, B$ ) and were trained until they reached asymptotic learning. Prior research shows that extensive training in orientation discrimination leads to large gains in performance (Vogels, 1990; Schoups et al., 1995) and to changes in orientation tuning in V1 and V4 neurons (Schoups et al., 2001; Raiguel et al., 2006). Tuning curves are most discriminative for orientation on their flanks, in V1 at $\sim 15^{\circ}$ from the preferred orientation (Fig. 1C,D), and training-induced steepening
$\Delta 0 \quad \Delta 0.5$

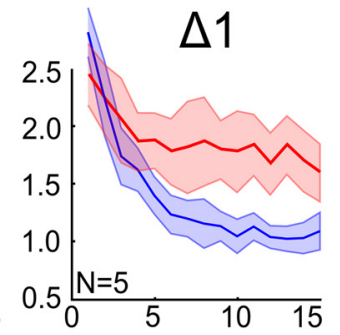

$\Delta 3$
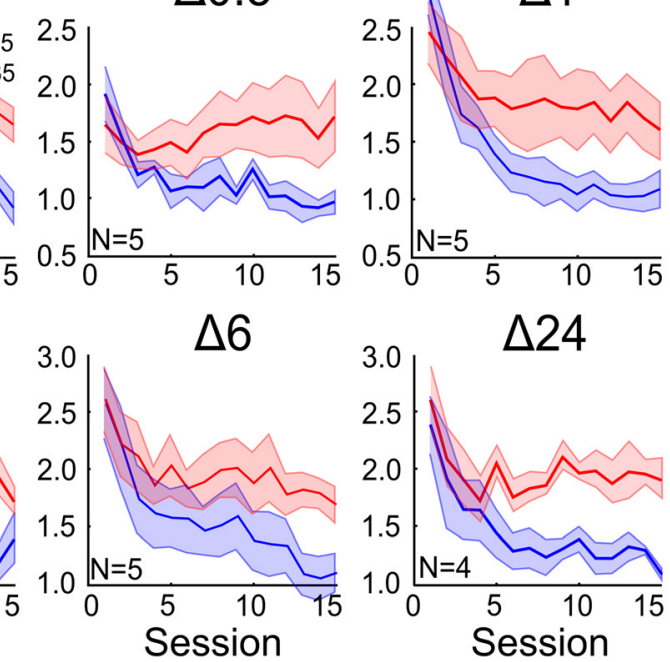

C

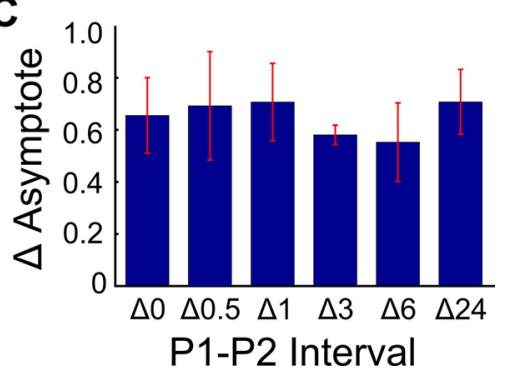

Figure 2. Behavioral interference during asymptotic learning. $A$, Interference for six different intervals between training period 1 (P1) and training period 2 (P2) ( $\Delta 0-\Delta 24 \mathrm{~h})$. Each panel (corresponding to one interval) shows the natural logarithm of the just noticeable difference [LN(JND)] plotted as a function of session in experimental quadrant (red line) and control quadrant (blue between intervals $\left(F_{(5,23)}=0.22, p=0.951\right)$. Shaded red and blue regions and error bars are standard errors; numbers in top right corner represent $N$ participants (conventions are similar for all figures).

of flanks overlapping the trained orientation has been proposed to underlie performance enhancements in orientation discrimination (Schoups et al., 2001; Raiguel et al., 2006). We tested whether training-induced performance gains in a first task would be decreased by training in a second task with stimuli chosen so that learning in the two tasks relied on steepening opposite tuning curve flanks of the same neurons. To that aim, we combined training in a first testing period (P1) at an oblique reference orientation with training in a second testing period (P2) at reference orientations deviating by $30^{\circ}$ clockwise or anticlockwise from oblique (Fig. 1D).

\section{Behavioral interference occurs during asymptotic learning and for all time intervals}

Figure $2 \mathrm{~A}$ shows the learning curves for $\mathrm{E}_{135}$ and $\mathrm{C}_{135}$ for all P1-P2 time intervals (five participants per interval, except for $\Delta 24 \mathrm{~h}$, where we had four participants). For $\Delta 0 \mathrm{~h}$, learning curves in the control quadrant showed fast learning in the first few sessions, followed by asymptotic leaning. There was little learning in the experimental quadrant, leading to strongly increased JNDs in experimental compared to control quadrant by the end of testing. Hence, performance enhancements induced by $\mathrm{P} 1$ training at $\mathrm{E}_{135}$ were strongly interfered with by $\mathrm{P} 2$ training at reference 
A
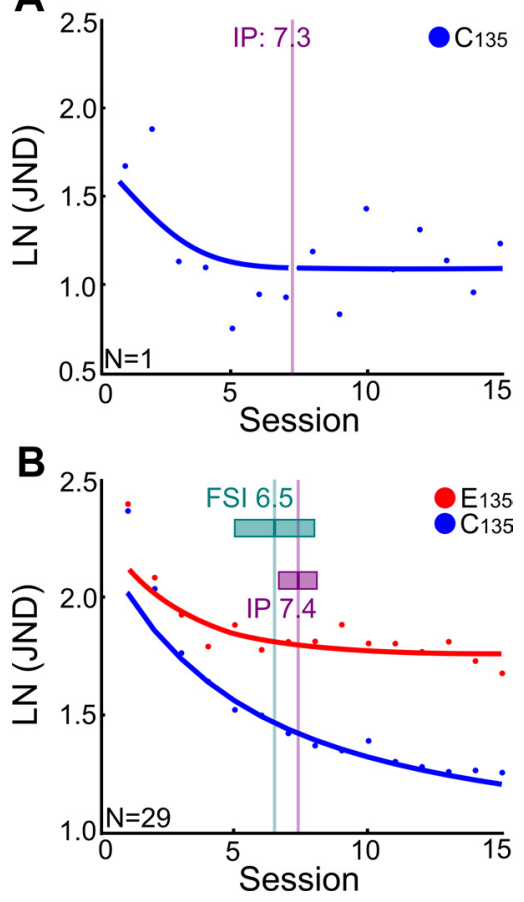

Figure 3. Significant interference starts at asymptotic learning. $A$, Illustration of the procedure to determine the beginning of asymptotic learning for the control condition at reference orientation $135^{\circ}\left(C_{135}\right)$ in a single participant. The beginning of asymptotic learning was defined as the IP of the learning curve. To determine the $\mathbb{I}$, we used a piecewise nonlinear regression fitting procedure (see Materials and Methods). The results of optimized nonlinear and linear fitting as well as the optimized transition point (the IP; vertical gray line) are shown. The IP was determined for all intervals between the first (P1) and second (P2) training periods for the $C_{135}$ condition, and the resulting IP (29 participants) was on average at session 7.4. $\boldsymbol{B}$, Comparison of the average inflection point with the average session in the course of learning at which the FSI is observed. The figure shows the data for the control condition $\mathrm{C}_{135}$ (blue dots) and the experimental condition $\mathrm{E}_{135}$ (red dots). For both conditions, the data were averaged over the different P1-P2 intervals $(0,0.5,1,3,6,24 \mathrm{~h})$, as these experimental conditions did not significantly differ from each other. The fitted curves represent the average result of piecewise fitting for $\mathrm{C}_{135}$ (blue) and $\mathrm{E}_{135}$ (red). The vertical lines respectively mark the average session of FSI (green line) and average inflection point of the control condition $C_{135}$ (IP, purple line) corresponding to the point at which initial fast learning is replaced with later asymptotic learning. While IP was based on estimates within each of 29 individuals, FSI was estimated in six groups of participants corresponding to the different P1-P2 delay conditions. The FSI was the first session in which paired-samples $t$ tests between the JNDs from $E_{135}$ and $C_{135}$ showed a statistically significant difference. Averaged over the six P1-P2 delay conditions, this occurred at session 6.5. The two horizontal boxes show the size of the $95 \%$ confidence intervals, for both FSI and IP. Their overlap indicates that the distribution and the averages of the FSI and IP are not significantly different. In addition, a $t$ test between the FSI and IP for the six different P1-P2 intervals showed that the average FSI is not significantly different from the average IP $(t=$ $-1.7399, \mathrm{df}=5, p=0.1424$; paired).

orientations $\mathrm{E}_{105}$ and $\mathrm{E}_{165}$. Strikingly, this pattern of results was present for all P1-P2 intervals. A repeated-measures ANOVA [Quadrant (2) $\times$ Interval (6) $\times$ Session (15)] showed significant effects for Session $\left(F_{(3.322,76.404)}=14.412, p=0.001\right)$, Quadrant $\left(F_{(1,23)}=68.375, p=0.001\right)$, and Quadrant $\times$ Session $\left(F_{(5.588,128.521)}=14.265, p=0.001\right)$, confirming behavioral interference. The effects of Interval $\left(F_{(5,23)}=1.936, p=0.126\right)$ and of the Interval $\times$ Session interaction $\left(F_{(16.610,76.404)}=1.098, p=\right.$ 0.372 ) were not significant, and therefore we pooled the dataset over intervals (Fig. $2 B$ ).

At the end of learning, there was a constant performance difference between $\mathrm{C}_{135}$ and $\mathrm{E}_{135}$, which was independent of the P1-P2 interval. Figure $2 C$ shows the difference between learning curve asymptotes in experimental and control quadrant averaged
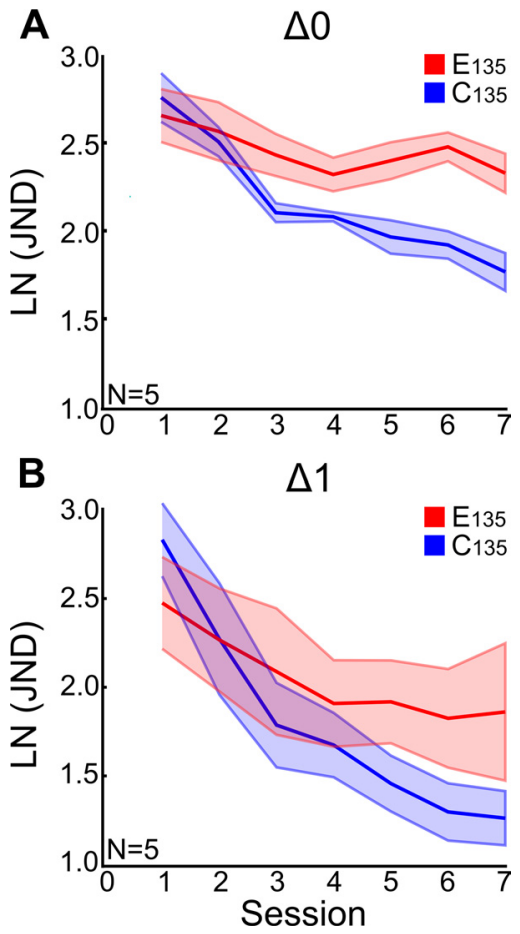

Figure 4. Comparing the fast learning part of the learning curves between the different P1-P2 intervals does not reveal time-limited consolidation. Here, a comparison of fast learning is shown at the $\Delta 0 \mathrm{~h}(\boldsymbol{A})$ and $\Delta 1 \mathrm{~h}$ intervals $(\boldsymbol{B})$. $\boldsymbol{A}$, The first seven sessions for the $\mathrm{E}_{135}$ and $\mathrm{C}_{135}$ conditions in the $\Delta 0 \mathrm{~h} \mathrm{P1-P2}$ interval, up to the average IP. $\boldsymbol{B}$, The first seven sessions for the $\Delta 1 \mathrm{~h}$ interval. These plots show the two intervals that are comparable to the intervals used in the paper of Seitz et al. (2005), who found time-dependent behavioral interference between two Vernier tasks during early learning. A repeated-measures ANOVA on our data [Condition $\left(\mathrm{E}_{135}, \mathrm{C}_{135}\right) \times \operatorname{Session}(7) \times \mathrm{P} 1-\mathrm{P} 2$ Interval $(\Delta 0 \mathrm{~h}, \Delta 1 \mathrm{~h})$ ] failed to find a significant interaction between Condition and Interval $\left(F_{(1,8)}=0.330, p=0.581\right)$. Also, for redundancy, a comparison was made between $\Delta 0$ with all other P1-P2 intervals in a combined repeatedmeasures ANOVA; again, the interaction between Condition and Interval was not significant $\left(F_{(5,23)}=0.374, p=0.861\right)$.

over the last eight sessions ( $\Delta$ Asymptote in ln units). A one-way ANOVA showed that there was no significant difference in the magnitude of $\Delta$ Asymptote between intervals $\left(F_{(5,23)}=0.22, p=\right.$ 0.951).

Further, in Figure 3 we show that interference started at asymptotic learning. Figure $3 A$ gives an illustration of the procedure to determine the beginning of asymptotic learning for the control condition at reference orientation $135^{\circ}\left(\mathrm{C}_{135}\right)$ in a single participant. First, the beginning of asymptotic learning was defined as the IP of the $\mathrm{C}_{135}$ learning curve by using a piecewise nonlinear regression fitting procedure (see Materials and Methods). Then a comparison was made of the average inflection point per P1-P2 interval with the average session in the course of learning at which the first significant interference (FSI) is observed (averaged over subjects for each of the six P1-P2 intervals). We found that the inflection point of the learning curve for $\mathrm{C}_{135}$, where asymptotic learning starts (session 7.4), was closely matched by the moment at which thresholds for $\mathrm{E}_{135}$ first significantly exceed those for $\mathrm{C}_{135}$ (session 6.5) $(t=-1.7399, \mathrm{df}=5$, $p=0.1424$; paired $t$ test on average FSI and IP per P1-P2 interval); this is in line with the idea that interference blocks learning when it is about to become asymptotic.

The finding that behavioral interference blocks asymptotic learning (Fig. $2 B$ ) suggests that it predominantly reflects interactions in early visual cortex (Karni and Bertini, 1997; Ahissar and 
Hochstein, 2004). The mechanism of interference may be related to $\mathrm{P} 1$ training at reference orientation $R$ and subsequent $\mathrm{P} 2$ training at $R \pm 30^{\circ}$ both requiring plasticity in neurons with preferred orientations at $R \pm 15^{\circ}$. In the $R \pm 15^{\circ}$ population (Fig. $1 D$, blue curves), $\mathrm{P} 1$ training should increase the slope of flanks in tuning curves overlapping with $R$, and $\mathrm{P} 2$ training should increase the slope of flanks overlapping with the $+30^{\circ}$ and $-30^{\circ}$ orientations. Our data suggest that one requirement counteracts the other, producing behavioral interference at $R$. Although we have based our explanatory model on V1 (Fig. 1D), contributions from other cortical areas with orientation selective neurons cannot be excluded.

The present study is the first to have described interference between two visual skill-learning tasks during prolonged, asymptotic learning. While we found interference to be time independent for time intervals between tasks of up to $24 \mathrm{~h}$, a prior study (Seitz et al., 2005) reported that behavioral interference between two Vernier tasks (after five daily sessions) disappeared with an interval between tasks of just $1 \mathrm{~h}$. Visual inspection of our data suggests that within the fast learning part of the learning curve, there could be a trend toward time-limited consolidation (Fig. 2A). To test this data trend, we ran a repeated-measures ANOVA on data from 10 subjects that were tested using the two P1-P2 intervals that are comparable to those used in the study of Seitz et al. (2005) [Condition $\left(\mathrm{E}_{135}, \mathrm{C}_{135}\right) \times$ Session $(7) \times \mathrm{P} 1-\mathrm{P} 2$ Interval $(\Delta 0 \mathrm{~h}, \Delta 1 \mathrm{~h})$ ] but failed to find a significant interaction between Condition and Interval $\left(F_{(1,8)}=0.330, p=0.581\right)$. Thus, the reduction in the difference between $\mathrm{E}_{135}$ and $\mathrm{C}_{135}$ conditions in Figure $4 \mathrm{~B}$ compared to Figure $4 A$, which might suggest time-limited consolidation during early learning, was not confirmed by statistical testing. For completeness, we also made a comparison of $\Delta 0$ with all other P1-P2 Intervals in a combined repeated-measures ANOVA, and again the interaction between Condition and Interval was not significant $\left(F_{(5,23)}=0.374, p=0.861\right)$. Hence, we failed to reproduce the trend for time-limited consolidation during early learning reported by Seitz et al. (2005) in a different task.

\section{Behavioral interference is stimulus dependent}

During the training at the $+30^{\circ}$ and $-30^{\circ}$ reference orientations, there are neurons for which the tuning curve flanks overlap with these two references (deviating $\pm 45^{\circ}$ from $R$; purple curves in Fig. $1 D$ ) that are not stimulated by other stimuli. They are likely sufficient in number to permit normal orientation discrimination learning at the $+30^{\circ}$ and $-30^{\circ}$ axes. Accordingly, $\mathrm{P} 2$ training of $\mathrm{E}_{105}$ and $\mathrm{E}_{165}$ should slow down learning at $\mathrm{E}_{135}$ induced by $\mathrm{P} 1$ training, but $\mathrm{P} 1$ training at $\mathrm{E}_{135}$ should not affect $\mathrm{P} 2$ training at $\mathrm{E}_{105}$ and $\mathrm{E}_{165}$. Figure $5 \mathrm{~A}$ shows exactly that result. Learning curves averaged over 29 subjects for conditions $\mathrm{E}_{105}, \mathrm{E}_{165}$, and $\mathrm{C}_{135}$ overlapped completely. A repeated-measures ANOVA showed neither a main effect of Condition $\left(\mathrm{E}_{105}, \mathrm{E}_{165}, \mathrm{C}_{135}\right)\left(F_{(2,56)}=0.049\right.$, $p=0.952)$ nor an interaction between Condition and Session $\left(F_{(8.857,248)}=1.521, p=0.142\right)$. Thus, the $\mathrm{E}_{105}$ and $\mathrm{E}_{165}$ training during $\mathrm{P} 2$ was unaffected by the preceding $\mathrm{E}_{135}$ training because the $\mathrm{E}_{135}$ training only affected half of the population contributing to the training in the $\mathrm{E}_{105}$ and $\mathrm{E}_{165}$ conditions. In the light of simulation studies indicating that on the order of 100 neurons permit normal orientation discrimination (Vogels, 1990), the normal training results at $\mathrm{E}_{105}$ and $\mathrm{E}_{165}$ are, in fact, unsurprising.

It could be argued, however, that JNDs in conditions $\mathrm{E}_{105}$ and $\mathrm{E}_{165}$ should be lower than those for $\mathrm{C}_{135}$ because of the "oblique effect" in orientation discrimination (Appelle, 1972). If this were true, the lack of differences among these conditions might therefore still hide an effect of interference by the $135^{\circ}$ reference orientation on the $105^{\circ}$ and $165^{\circ}$ reference orientations. To investigate whether the performance on the $\mathrm{P} 2$ conditions $105^{\circ}$ or $165^{\circ}$ suffered from interference, we retested the five subjects that already had been trained on the $\Delta 0 \mathrm{~h}$ P1-P2 interval (Fig. $5 A, B$ ). This time, they were trained on the $105^{\circ}$ orientation in a naive visual quadrant $\left(\mathrm{E}_{105}\right)$ where no other (potentially interfering) training on any other orientations had taken place. Performance in this condition was compared to new training at the $135^{\circ}$ reference orientation in another naive visual quadrant $\left(\mathrm{C}_{135}\right)$. The naive quadrants used were the two lower quadrants.

The data confirm that the potential for behavioral interference decreases the less skill memories for the two tasks depend on the same neural population (O'Reilly and Rudy, 2001). We tested this further in seven participants by increasing the orientation difference between the reference orientation used during P1 training and the reference orientation used during P2 training. In a first Experimental quadrant, we used a $90^{\circ}$ difference between the reference orientation during $\mathrm{P} 1$ training $\left(\mathrm{E} 90_{135}\right)$ and the reference during $\mathrm{P} 2$ training $\left(\mathrm{E} 90_{45}\right)$. In a second Experimental quadrant, we used a $30^{\circ}$ difference between the $\mathrm{P} 1$ reference orientation $\left(\mathrm{E} 30_{135}\right)$ and the P2 orientations (E30 105 and $\left.\mathrm{E} 30_{165}\right)$. Upper left and right quadrants served as experimental quadrants and the control condition $\mathrm{C}_{135}$ was in one of the lower quadrants (Fig. 6A). Figure $6 B$ shows that learning curves from $\mathrm{P} 1$ training at $\mathrm{C}_{135}$ and $\mathrm{E} 0_{135}$ did not differ $\left(F_{(1,6)}=0.237, p=0.664\right.$; compare gray and blue curves in Fig. $6 \mathrm{~B}$ ), while the JNDs of $\mathrm{C}_{135}$ and E30 ${ }_{135}$ did differ $\left(F_{(1,6)}=12.788, p=0.012\right.$; compare red and blue curves in Fig. $6 B$ ).

To verify that the absence of interference was not confounded by the fact that four of the seven subjects tested were presented with only half of the trials during P2 training (a block of four JNDs at of $\mathrm{E} 0_{45}$ ) compared to the number of trials given in P2 training in our standard design (four JNDs at $105^{\circ}$ and four JNDs at $165^{\circ}$ references), we performed an extra analyses on the data. 

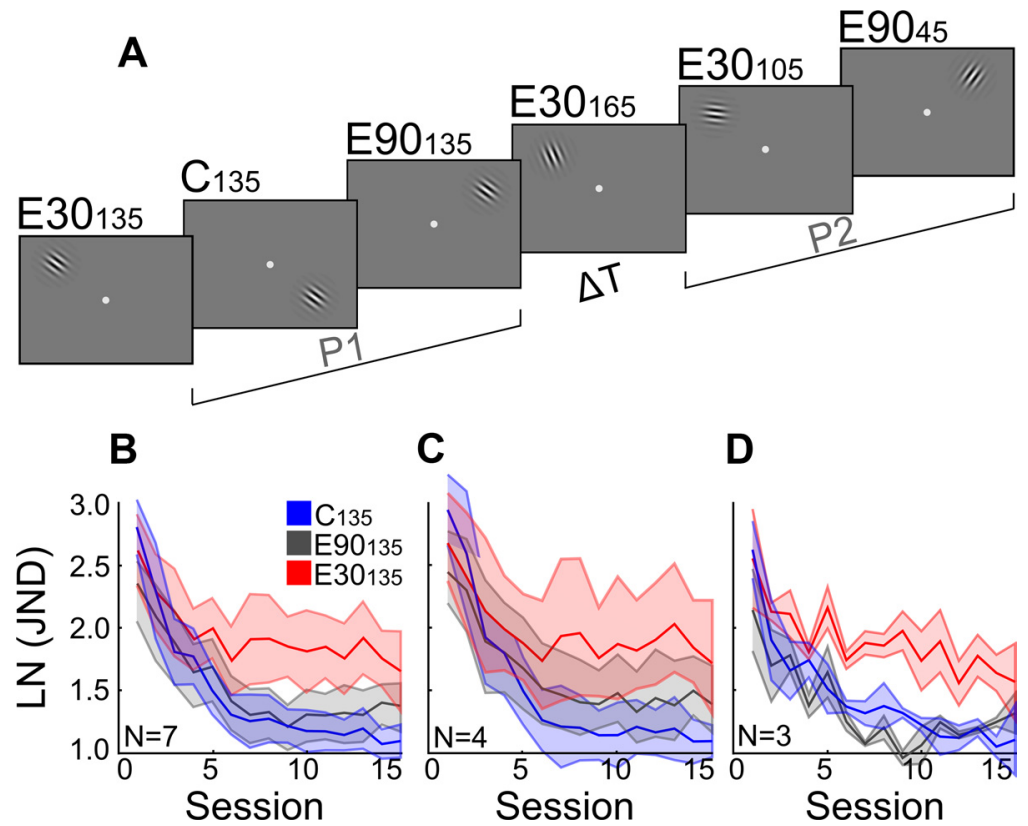
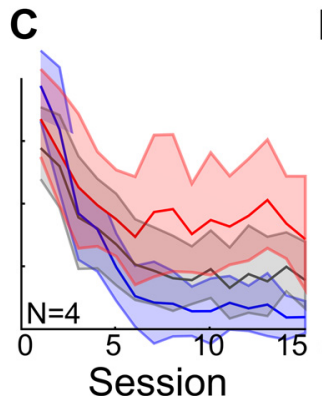

D

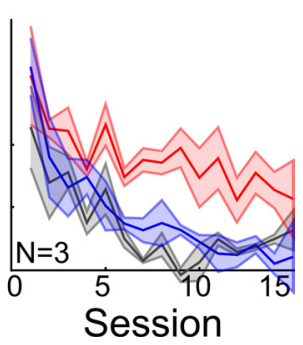

Figure 6. Double training does not cause behavioral interference. $A$, Experimental design used to replicate interfering effects of two blocks of training in $\mathrm{P} 2$ at reference orientations that differ by $30^{\circ}$ from $135^{\circ}\left(\mathrm{C}_{3} \mathrm{O}_{135}\right.$ in P1, $\mathrm{E} 3 \mathrm{O}_{105}$ and $\mathrm{E3} \mathrm{1}_{165}$ in P2), and to compare these with interfering effects of a single block or two blocks in $\mathrm{P} 2$ at a reference orientation differing by $90^{\circ}$ from $135^{\circ}$ $\left(E 90_{135}\right.$ in $\mathrm{P} 1, \mathrm{E} \mathrm{O}_{45}$ in P2). Thus, while each stimulus display in Figure $6 \mathrm{~A}$ corresponds to four JNDs, display $E 90_{45}$ was tested in either four or eight JNDs. The number following " $E$ " refers to the orientation difference between reference orientations used during $\mathrm{P} 1$ and $\mathrm{P} 2$ training in the same location. $\boldsymbol{B}$, Training in orientation discrimination with orthogonal reference orientations during P1 and $\mathrm{P} 2$ does not cause behavioral interference $(N=7)$. The figure shows learning curves for $\mathrm{P} 1$ training at the $135^{\circ}$ reference orientation in the control quadrant $\left(C_{135}\right)$, for $P 1$ training at the $135^{\circ}$ reference orientation in the experimental quadrant where $P 2$ training was performed with an orthogonal $45^{\circ}$ reference $\left(\mathrm{E} \mathrm{O}_{135}\right)$ (either 4 or $8 \mathrm{JNDs}$ ), and for $\mathrm{P} 1$ training at the $135^{\circ}$ reference orientation in the experimental quadrant where $\mathrm{P} 2$ training was performed at $\pm 30^{\circ}$ references $\left({\mathrm{E} 3 \mathrm{O}_{135}}_{135}\right)$. Learning curves for $\mathrm{E} 0_{135}$ (dark gray) and $\mathrm{C}_{135}$ (blue) overlap. C, Effect of training with a double block (8 JNDs) of $\mathrm{P} 2$ training at a $45^{\circ}$ reference $\left(\mathrm{E} \mathrm{O}_{45}\right.$ ) on learning rate in the preceding P1 training condition at $135^{\circ}\left(E 90_{135}\right)$. D. Effect of training with a single block (4 JNDs) of P2 training at a $45^{\circ}$ reference $\left(\mathrm{E} \mathrm{O}_{45}\right)$ in otherwise the same experiment. In both datasets, the $\mathrm{E}{ }_{135}$ condition (dark gray line) is compared with the standard control condition $\mathrm{C}_{135}$ (blue line), and with the standard interference condition $\mathrm{E}^{3} \mathrm{O}_{135}$ (red line) in which P1 training at $135^{\circ}$ was followed by a block ( 4 JNDs) of $\mathrm{P} 2$ training at $105^{\circ}$ and a block at 165 . A repeated-measures ANOVA [Double-Training (yes, no) $\times$ Condition $\left(C_{135}, E_{135}\right) \times$ Session (15)] showed that neither the main effect of Condition $\left(F_{(1,5)}=\right.$ $0.95, p=0.770)$ nor the Condition $\times$ Double-Training interaction $\left(F_{(1,5)}=2.946, p=0.147\right)$ was significant.

The data of the same seven subjects were reanalyzed separating the subjects in two groups according to the number of trials they trained on in the P2 period. The results are plotted in Figure 6, $C$ (eight JNDs of ${\mathrm{E} 90_{45}}_{4}$ ) and $D$ (eight JNDs of ${\mathrm{E} 90_{45}}_{4}$ ), and show that the differences between $\mathrm{E} 90_{135}$ and $\mathrm{C}_{135}$ conditions are still negligible and did not increase when the amount of training on $\mathrm{E} 90_{45}$ was doubled in the P2 interval. Statistical evaluation confirmed that $\mathrm{P} 1$ training at the $135^{\circ}$ reference orientation is about equally unaffected by one or two blocks of $\mathrm{P} 2$ training at the orthogonal reference orientation (compare $\mathrm{E} 0_{135}$ with $\mathrm{C}_{135}$ in Fig. $6 C, D$ ). Specifically, a repeated-measures ANOVA [Double-Training (yes, no) $\times$ Condition $\left(\mathrm{C}_{135}\right.$, E90 $\left._{135}\right) \times$ Session (15)] showed that neither the main effect of Condition $\left(F_{(1,5)}=0.95, p=0.770\right)$ nor the Condition $\times$ Double-Training interaction $\left(F_{(1,5)}=2.946, p=\right.$ 0.147 ) were significant.

\section{Discussion}

We have studied factors contributing to LTM formation in a perceptual skill-learning task using a behavioral interference paradigm. Skill is one of many forms of LTM, which has been subdivided in two main classes: explicit (declarative) and implicit (nondeclarative) memory (Kandel et al., 2000; Squire, 2004). Declarative memory includes memory for facts and events, and implicit memory includes associative and nonassociative learning as well as motor and perceptual skill learning. Theories of LTM distinguish between the manipulation of information for storage (encoding), and storage itself (consolidation) (Atkinson and Shiffrin, 1968; Craik and Lockhart, 1972). The present study has focused on the processes that consolidate skill memories. Consolidation exists in both declarative (Squire, 1992; Squire and Alvarez, 1995) and implicit memory (Brashers-Krug et al., 1996; Karni, 1996; Karni et al., 1998; Robertson, 2004; Robertson et al., 2004), and refers to a process during which initially labile memory traces are transformed to stable memory traces. Because consolidation is thought to take place in a time-limited window extending beyond the experience by several hours (Dudai, 2004), behavioral interference is expected when a second experience falls within the consolidation window of a preceding experience. However, in our skill-learning study, we found that training in an orientation discrimination task could be interfered with by training in a second set of orientation discrimination tasks across a broad range of time intervals between training in P1 and P2 $(0,0.5,1,3,6$, and $24 \mathrm{~h}$ ). Moreover, although varying the time interval between P1 and P2 did not modulate interference, stimulus similarity did, and increasing the stimulus orientation difference from $30^{\circ}$ to $90^{\circ}$ prevented interference.

To interpret our data, it is useful to distinguish cellular and systems-level processes contributing to LTM consolidation. At the cellular level, an experience triggers the expression of Immediate Early Genes (IEGs) whose protein products can act as transcription factors for Late Genes (LGs) involved in functional and structural modifications of synaptic strength between neurons (Dudai, 2004). Gene expression and protein synthesis associated with these initial cascades take place within minutes (IEGs) to hours (LGs) after neuronal stimulation, and disruption of these processes during or immediately after an experience interferes with memory consolidation (Duncan, 1949; Agranoff et al., 1965; Bütefisch et al., 2000; Muellbacher et al., 2002; Luft et al., 2004). Predictions of behavioral interference in skill-learning experiments seem to be based on this initial molecular cascade taking place over several hours following an experience (Brashers-Krug et al., 1996; Shadmehr and Holcomb, 1997; Seitz et al., 2005). However, cellular plasticity related to LTM formation may comprise multiple periods during waking (Bourtchouladze et al., 1998; Korman et al., 2003; Wanisch et al., 2008) and sleep (Karni et al., 1994; Stickgold et al., 2000; Gervan and Kovacs, 2010). Therefore, the notion of a single time-limited consolidation window cannot guide precise predictions about the time window in which behavioral interference would take place.

In addition, systems-level processes contribute to memory formation. Systems-level considerations are an important aspect in theories of episodic memory formation in which a slow trans- 
fer of memory traces from hippocampus to cortex is proposed (Zola-Morgan and Squire, 1990; Squire and Alvarez, 1995), though this proposal is debated (Nadel and Moscovitch, 1997; Nadel et al., 2000). Strengthening of cortical memory traces is also thought to involve "replay," a term that refers to the reinstantiation of neural activity elicited by a prior experience. Replay is coordinated by lowfrequency oscillatory activity (Jensen, 2006; Sirota et al., 2008), and has been shown in both hippocampal-based memory formation (Wilson and McNaughton, 1994; Hoffman and McNaughton, 2002) and skill-related memory formation (Stickgold et al., 2000; Yotsumoto et al., 2009). Another important systems-level factor is the requirement to segregate different memory traces. This is well recognized in the field of episodic memory formation (O'Reilly and Rudy, 2001), but has received less attention in the field of (perceptual) skill learning. During asymptotic perceptual learning, sensory neurons involved with acquisition during task performance with a specific stimulus are thought to contribute to memory formation (Karni and Bertini, 1997). This permitted predictions of specific stimulus conditions in which overlap of memory traces and behavioral interference would occur, and in which time-limited consolidation could be tested.

Because training induces slope changes in the flanks of orientation tuning curves with optimal orientations at $\pm 15^{\circ}$ from the trained reference $(R)$ orientation (Schoups et al., 2001), we predicted behavioral interference when $\mathrm{P} 1$ training at $R$ was followed by $\mathrm{P} 2$ training at $R \pm 15^{\circ}$ (see Fig. 1 legend). We confirmed this prediction for all six $\mathrm{P} 1-\mathrm{P} 2$ time intervals tested. The stimulus specificity of interference was confirmed by the finding that training with a $90^{\circ}$ difference between the reference orientations for P1 and P2 training, chosen to avoid overlap between memory traces, did not cause interference at the $1 \mathrm{~h} \mathrm{P1-P} 2$ time interval. In addition, $\mathrm{P} 2$ training at reference orientations $105^{\circ}$ and $165^{\circ}$ was not affected by $\mathrm{P} 1$ training at the $135^{\circ}$ reference orientation. This may be due to half of the neuronal population associated with references $105^{\circ}$ and $165^{\circ}$ remaining unaffected by the training at the $135^{\circ}$ reference, which according to computational models (Vogels, 1990) is sufficient to permit normal orientation discrimination performance. Together, these findings show that the amount of overlap between populations involved in memory formation in low-level visual cortex (V1) is a highly determining factor for interference. Note that although our results suggest retrograde interference ( $\mathrm{P} 2$ training affecting $\mathrm{P} 1$ training) rather than anterograde interference (P1 training affecting $\mathrm{P} 2$ training), the distinction between the two is difficult if the main factor leading to interference is stimulus-determined.

Our finding of equal behavioral interference for a range of time intervals is difficult to interpret in terms of the classical concept of time-limited consolidation. There is no doubt that time-dependent cellular processes take place in a behavioral interference experiment (likely in multiple periods). However, their interaction with systems-level factors makes the contributions of both factors difficult to separate. For short P1-P2 intervals, behavioral interference is likely to be related to interference with more short-lived cellular consolidation processes, but at longer time intervals (especially $24 \mathrm{~h}$ ), it may predominantly reflect the recruitment of a population of neurons that has become wired for a different task. However, regardless of the time interval between first and second training, overlap of memory traces is a precondition for interference to take place. Possibly, interference may be avoided by incorporating long periods without training (e.g., a week) after each pair of P1-P2 training sessions. This may permit segregation of memory traces through a slow competitive process in which memory traces may also become sparser. Even if this is true, the most straightforward interpretation of our data is that the behavioral interference observed in our study is stimulus-related and reflects a limit in the simultaneous representation of expertise on different skills in a single neuronal population (Ni and Maunsell, 2010).

This interpretation implies that memory traces remain highly malleable and far from immune for interference by other memory traces, even at asymptotic levels of expertise. In the domain of episodic memory formation, this idea has been proposed in the multiple-trace theory (Lewis, 1979; Nadel and Moscovitch, 2001). Here, previously consolidated episodic memories when retrieved become subject to reconsolidation (Lee et al., 2004; Lee, 2008), a process during which the original memory is modified. A related distinction has been proposed between active and inactive memory traces (Lewis, 1979; Caithness et al., 2004; Xu et al., 2009; Yang et al., 2009). In this framework, it is proposed that memory traces are active when they are formed, become inactive when they are not accessed, and are reactivated when retrieved (Nader et al., 2000; Nader, 2003). This reactivation returns the memory trace to a labile state in which it can be modified. Recent studies have shown that sensory experience leaves traces in the form of the size and number of synapses and dendritic spines ( $\mathrm{Xu}$ et al., 2009; Yang et al., 2009), and that the size of spines is related to the age of memories so that spine size may be a correlate of trace reactivation (Alvarez and Sabatini, 2007; Hofer et al., 2009). In the domain of skill learning, the malleability of memory traces provides a form of flexibility that can be advantageous. It permits efficient memory storage, because increases in expertise will lead to updating of a single memory rather than the creation of new memories for each level of increased skill, and replacement of expertise in an old skill with expertise required for a new skill.

In conclusion, we have provided the first full description of behavioral interference during asymptotic learning of two visual skill-learning tasks. We found that the extent of overlap between sensory neuronal populations stimulated in two competing tasks was the best predictor for the magnitude of behavioral interference, regardless of the state of memory formation for the first task when training in the second task was started. Hence, behavioral interference paradigms are not a sensitive approach to test the existence of specific time-limited consolidation processes. Instead, interference paradigms can help to identify limits in the capacity of neuronal subpopulations to simultaneously represent expertise for different skills during asymptotic learning.

\section{References}

Aberg KC, Herzog MH (2010) Does perceptual learning suffer from retrograde interference? PLoS One 5:e14161.

Agranoff BW, Davis RE, Brink JJ (1965) Memory fixation in the goldfish. Proc Natl Acad Sci U S A 54:788-793.

Ahissar M, Hochstein S (2004) The reverse hierarchy theory of visual perceptual learning. Trends Cogn Sci 8:457-464.

Alvarez VA, Sabatini BL (2007) Anatomical and physiological plasticity of dendritic spines. Annu Rev Neurosci 30:79-97.

Appelle S (1972) Perception and discrimination as a function of stimulus orientation-oblique effect in man and animals. Psychol Bull 78:266-278.

Atkinson RC, Shiffrin RM (1968) Human memory: a proposed system and its control processes. In: The psychology of learning and motivation (Spence KW, Spence JT, eds). London: Academic.

Bourtchouladze R, Abel T, Berman N, Gordon R, Lapidus K, Kandel ER (1998) Different training procedures recruit either one or two critical periods for contextual memory consolidation, each of which requires protein synthesis and PKA. Learn Mem 5:365-374.

Brashers-Krug T, Shadmehr R, Bizzi E (1996) Consolidation in human motor memory. Nature 382:252-255.

Bütefisch CM, Davis BC, Wise SP, Sawaki L, Kopylev L, Classen J, Cohen LG 
(2000) Mechanisms of use-dependent plasticity in the human motor cortex. Proc Natl Acad Sci U S A 97:3661-3665.

Caithness G, Osu R, Bays P, Chase H, Klassen J, Kawato M, Wolpert DM, Flanagan JR (2004) Failure to consolidate the consolidation theory of learning for sensorimotor adaptation tasks. J Neurosci 24:8662-8671.

Craik FIM, Lockhart RS (1972) Levels of processing: a framework for memory research. J Verb Learn Verb Behav 11:671-684.

David SV, Hayden BY, Gallant JL (2006) Spectral receptive field properties explain shape selectivity in area V4. J Neurophysiol 96:3492-3505.

Doyon J, Penhune V, Ungerleider LG (2003) Distinct contribution of the cortico-striatal and cortico-cerebellar systems to motor skill learning. Neuropsychologia 41:252-262.

Dudai Y (2004) The neurobiology of consolidations, or, how stable is the engram? Annu Rev Psychol 55:51-86.

Duncan CP (1949) The retroactive effect of electroshock on learning. J Comp Physiol Psychol 42:32-44.

Fahle M, Poggio T (2002) Perceptual learning. Cambridge, MA: MIT Press.

Fine I, Jacobs RA (2002) Comparing perceptual learning across tasks: a review. J Vis 2:190-203.

Gervan P, Kovacs I (2010) Two phases of offline learning in contour integration. J Vis 10:24.

Goedert KM, Willingham DB (2002) Patterns of interference in sequence learning and prism adaptation inconsistent with the consolidation hypothesis. Learn Mem 9:279-292.

Hochstein S, Ahissar M (2002) View from the top: hierarchies and reverse hierarchies in the visual system. Neuron 36:791-804.

Hofer SB, Mrsic-Flogel TD, Bonhoeffer T, Hübener M (2009) Experience leaves a lasting structural trace in cortical circuits. Nature 457:313-317.

Hoffman KL, McNaughton BL (2002) Coordinated reactivation of distributed memory traces in primate neocortex. Science 297:2070-2073.

Hung SC, Seitz AR (2011) Retrograde interference in perceptual learning of a peripheral hyperacuity task. PLoS One 6:e24556.

Jensen O (2006) Maintenance of multiple working memory items by temporal segmentation. Neuroscience 139:237-249.

Kandel ER, Kupfermann I, Iversen S (2000) Learning and memory. In: Principles of neural science (Kandel ER, Schwartz JH, Jessell TM, eds), New York: McGraw-Hill.

Karni A (1996) The acquisition of perceptual and motor skills: a memory system in the adult human cortex. Brain Res Cogn Brain Res 5:39-48.

Karni A, Bertini G (1997) Learning perceptual skills: behavioral probes into adult cortical plasticity. Curr Opin Neurobiol 7:530-535.

Karni A, Tanne D, Rubenstein BS, Askenasy JJ, Sagi D (1994) Dependence on REM sleep of overnight improvement of a perceptual skill. Science 265:679-682.

Karni A, Meyer G, Rey-Hipolito C, Jezzard P, Adams MM, Turner R, Ungerleider LG (1998) The acquisition of skilled motor performance: fast and slow experience-driven changes in primary motor cortex. Proc Natl Acad Sci U S A 95:861-868.

Korman M, Raz N, Flash T, Karni A (2003) Multiple shifts in the representation of a motor sequence during the acquisition of skilled performance. Proc Natl Acad Sci U S A 100:12492-12497.

Lee JL (2008) Memory reconsolidation mediates the strengthening of memories by additional learning. Nat Neurosci 11:1264-1266.

Lee JL, Everitt BJ, Thomas KL (2004) Independent cellular processes for hippocampal memory consolidation and reconsolidation. Science 304:839-843.

Lewis DJ (1979) Psychobiology of active and inactive memory. Psychol Bull 86:1054-1083.

Luft AR, Buitrago MM, Ringer T, Dichgans J, Schulz JB (2004) Motor skill learning depends on protein synthesis in motor cortex after training. J Neurosci 24:6515-6520.

Muellbacher W, Ziemann U, Wissel J, Dang N, Kofler M, Facchini S, Boroojerdi B, Poewe W, Hallett M (2002) Early consolidation in human primary motor cortex. Nature 415:640-644.

Nadel L, Moscovitch M (1997) Memory consolidation, retrograde amnesia and the hippocampal complex. Curr Opin Neurobiol 7:217-227.

Nadel L, Moscovitch M (2001) The hippocampal complex and long-term memory revisited. Trends Cogn Sci 5:228-230.
Nadel L, Samsonovich A, Ryan L, Moscovitch M (2000) Multiple trace theory of human memory: computational, neuroimaging, and neuropsychological results. Hippocampus 10:352-368.

Nader K (2003) Neuroscience: re-recording human memories. Nature 425:571-572.

Nader K, Schafe GE, LeDoux JE (2000) The labile nature of consolidation theory. Nat Rev Neurosci 1:216-219.

Ni AM, Maunsell JH (2010) Microstimulation reveals limits in detecting different signals from a local cortical region. Curr Biol 20:824-828.

O’Reilly RC, Rudy JW (2001) Conjunctive representations in learning and memory: principles of cortical and hippocampal function. Psychol Rev 108:311-345.

Raiguel S, Vogels R, Mysore SG, Orban GA (2006) Learning to see the difference specifically alters the most informative V4 neurons. J Neurosci 26:6589-6602

Robertson EM (2004) Skill learning: putting procedural consolidation in context. Curr Biol 14:R1061-R1063.

Robertson EM, Pascual-Leone A, Miall RC (2004) Current concepts in procedural consolidation. Nat Rev Neurosci 5:576-582.

Schoups AA, Vogels R, Orban GA (1995) Human perceptual learning in identifying the oblique orientation: retinotopy, orientation specificity and monocularity. J Physiol 483:797-810.

Schoups A, Vogels R, Qian N, Orban G (2001) Practising orientation identification improves orientation coding in V1 neurons. Nature 412:549-553.

Seitz AR, Yamagishi N, Werner B, Goda N, Kawato M, Watanabe T (2005) Task-specific disruption of perceptual learning. Proc Natl Acad Sci U S A 102:14895-14900.

Shadmehr R, Holcomb HH (1997) Neural correlates of motor memory consolidation. Science 277:821-825.

Sirota A, Montgomery S, Fujisawa S, Isomura Y, Zugaro M, Buzsáki G (2008) Entrainment of neocortical neurons and gamma oscillations by the hippocampal theta rhythm. Neuron 60:683-697.

Squire LR (1992) Memory and the hippocampus: a synthesis from findings with rats, monkeys, and humans. Psychol Rev 99:195-231.

Squire LR (2004) Memory systems of the brain: a brief history and current perspective. Neurobiol Learn Mem 82:171-177.

Squire LR, Alvarez P (1995) Retrograde amnesia and memory consolidation: a neurobiological perspective. Curr Opin Neurobiol 5:169-177.

Stickgold R, James L, Hobson JA (2000) Visual discrimination learning requires sleep after training. Nat Neurosci 3:1237-1238.

Vogels R (1990) Population coding of stimulus orientation by striate cortical cells. Biol Cybern 64:25-31.

Vogels R, Orban GA (1985) The effect of practice on the oblique effect in line orientation judgments. Vision Res 25:1679-1687.

Wanisch K, Wotjak CT, Engelmann M (2008) Long-lasting second stage of recognition memory consolidation in mice. Behav Brain Res 186: 191-196.

Willingham DB (1999) The neural basis of motor-skill learning. Curr Dir Psychol Sci 8:178-182.

Wilson MA, McNaughton BL (1994) Reactivation of hippocampal ensemble memories during sleep. Science 265:676-679.

Xu T, Yu X, Perlik AJ, Tobin WF, Zweig JA, Tennant K, Jones T, Zuo Y (2009) Rapid formation and selective stabilization of synapses for enduring motor memories. Nature 462:915-919.

Yang G, Pan F, Gan WB (2009) Stably maintained dendritic spines are associated with lifelong memories. Nature 462:920-924.

Yotsumoto Y, Sasaki Y, Chan P, Vasios CE, Bonmassar G, Ito N, Náñez JE Sr, Shimojo S, Watanabe T (2009) Location-specific cortical activation changes during sleep after training for perceptual learning. Curr Biol 19:1278-1282.

Zhang JY, Kuai SG, Xiao LQ, Klein SA, Levi DM, Yu C (2008) Stimulus coding rules for perceptual learning. PLoS Biol 6:e197.

Zola-Morgan SM, Squire LR (1990) The primate hippocampal formation: evidence for a time-limited role in memory storage. Science 250:288-290. 